\title{
Urban vulnerability and resilience to climate change
}

\author{
S. Rafael, H. Martins, C. Borrego \& M. Lopes \\ CESAM \& Department of Environment and Planning, \\ University of Aveiro, Portugal
}

\begin{abstract}
Notwithstanding the increasing number of studies on vulnerability, there has been relatively little research focused specifically on urban vulnerability to climate change. The different lineages explored offer insights into the factors that control urban vulnerability to climate change and weather extremes effects, providing a framework to consider resilience. A new vulnerability paradigm is emerging as a useful tool for city decision-makers to analyse how their city should seek to adapt to the anticipated impacts of climate change. In the scope of the project CLICURB (Urban atmospheric quality, climate change and resilience) urban vulnerability is explored with respect to recent climate change and the relations between the concepts of vulnerability, resilience and adaptive capacity. This review and analysis contributes to the understanding of, and the general agreement amongst research communities, about the definition of these key concepts with respect to the climate change literature in urban areas.

Keywords: climate change, resilience, urban areas, vulnerability.
\end{abstract}

\section{Introduction}

Urban areas are home to over half of the world population and are at the forefront of climate change concerns. Climate change (CC) exerts added stress on urban areas through, among others, increased numbers of heat waves and more frequent and intense droughts and inland floods. For coastal cities, enhanced sea level rise and storm surges affecting inhabitants and essential infrastructure, property and ecosystems, are also a concern [1]. There are also special features of cities related to $\mathrm{CC}$, including the enhancement of the urban heat island (UHI) effect and the exacerbation of air pollution, the increase of energy demand and consequently of emissions of greenhouse gases (GHG), and the vulnerability caused by growing 
urban populations and high population density. These challenges highlight the need for cities to rethink how people are protected, how infrastructure investments are prioritized, and how climate will affect long-term growth and development plans.

Cities are responsible for around $70 \%$ of global GHG emissions, and given current demographic trends, this level is likely to increase over time. The nature of the built environment, structural aspects such as streets, buildings, and infrastructure, modify significantly the emission of GHG and amplify CC impacts. The structure and materials, the shape and orientation of buildings and the streetscapes can increase the need for cooling and heating of buildings. Areas of impervious surfaces can intensify flooding and are direct determinants of the UHI effect, particularly because the built urban contributes to the reduction of evaporation and to increased sensible heat emissions to the urban boundary layer. The presence or lack of street trees and parks, and the extent of wastewater and drainage systems, can either enhance or impede the natural processes of evapotranspiration, in addition to amplifying drought and flooding effects [2].

Despite being clearly vulnerable to the effects of $\mathrm{CC}$, cities are also uniquely positioned to take a leadership role in anticipating climatic variability and change, designing resilience into their development to lead to more robust projects that serve their populations better. By understanding, planning and adapting to a changing climate, individuals and societies can take advantage of opportunities and reduce risks.

Notwithstanding the increasing number of studies on vulnerability, there has been relatively little research focused specifically on urban vulnerability to $\mathrm{CC}$ as well as its linkage with other key concepts that appear within the CC literature (notable exceptions include [3-5]). The project, CLICURB - urban atmospheric quality, climate change and resilience - aims to bridge gaps between the implications of global CC trends and urban development through the inclusion of adaptation strategies. This requires exploration of the concepts of vulnerability, adaptive capacity and resilience. This paper presents a review of these concepts applied to urban areas in the context of CC.

\section{Vulnerability of urban areas}

Cities are the key to Europe's economy and innovation as well as the locus of major economic assets. On the other hand, the cities are the place where most people in Europe will experience CC impacts as they accommodate around three quarters of the population, a share which is expected to increase. The combination of population density with the economic assets and city services/systems (e.g. energy, water, waste, food and other) makes urban areas highly vulnerable to both current climate variability and to $\mathrm{CC}[6]$.

\subsection{Concepts}

Studies on urban vulnerability tend to characterize it in negative terms, as the possibility to be harmed; that is, as the degree to which a system (e.g. city, population, infrastructure, economic sector) is susceptible to, and is unable to cope 
with, adverse effects of a single or of several stressors [7]. The concept of vulnerability includes a complex and dynamic reality. Besides referring to the possibility that a system is negatively affected by something (a stressor), it is also a relative property defining both the sensitivity and the capacity to deal with that stress. Therefore, vulnerability cannot be defined by the stressor alone, nor can it be represented strictly by internal properties of the system being stressed [8]. Instead, it must be considered as an interaction of these factors, expressed by the sum of several dimensions: exposure, sensitivity, and capacity to adapt (Figure 1).

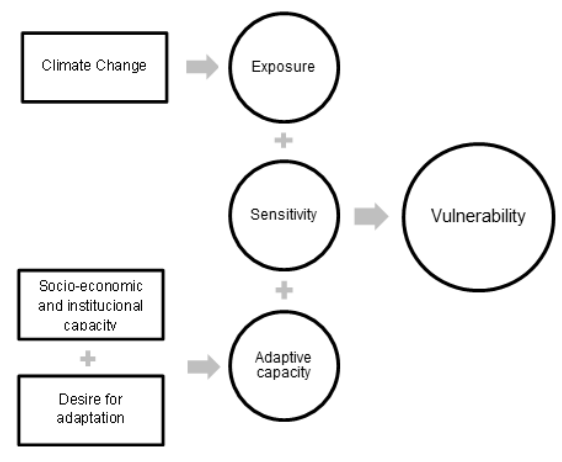

Figure 1: A conceptual framework of urban vulnerability to global climate and environmental change (source: adapted from [8]).

Exposure and sensitivity are related properties of a system and are dependent on the interaction between the characteristics of the system and on the attributes of the surrounding environment, namely climate stimulus. Exposure refers to the degree, duration, and/or extent to which the system is in contact with, or subject to, the perturbation [9]. It is a property of the relationship between the system and its environment (specifically between the system and the perturbation), rather than a property of the system. The characterization of vulnerability (e.g. indices, maps, etc.) needs to take into account the full set of possible combinations of situations, and must be changed if the distribution of exposure changes (for example, when alternative climate scenarios are examined).

The concept of sensitivity varies between authors. According to the IPCC [10], sensitivity is "the degree to which a system is affected, either adversely or beneficially, by climate-related stimuli". The effect may be direct (e.g. an increase of photochemical pollutants concentration in response to a change in the mean, range, or variability of temperature) or indirect (e.g. an increase of atmospheric pollutants concentrations caused by an increase in the energy consumption due to temperature rise). Gallopín [11] defines sensitivity as "the degree to which the system is modified or affected by an internal or external disturbance or set of disturbances". Conceptually, it can be described as the amount of transformation of the system per unit of the change in a given factor, but in the simplest case it only specifies if a system is or not responsive to a particular stressor. In this context, sensitivity is an attribute of the system; distinguished from its capacity of 
response (the actual transformation is different, depending on the capacity of response of the system). It is an inherent property of the system, once exist prior to the perturbation, separate from exposure.

The other central concept related to vulnerability is adaptive capacity, also referred to as "coping capacity" [12] or "capacity of response" [11]. As noted by Smit and Wandel [13], some authors applied these last terms to shorter-term capacity or the ability to just survive, and employ the adaptive capacity for longerterm or more sustainable adjustments. Given this lack of agreement the term used here for this aspect of vulnerability is adaptive capacity (of the system to the perturbations). In general, adaptive capacity is defined as "the ability of a system to adjust to climate change (including climate variability and extremes) to moderate potential damages, to take advantage of opportunities, or to cope with the consequences" [14]. Adaptive capacity, like sensitivity, is clearly an inherent property of the system that exists prior to the perturbation.

"Adaptive capacity" can be assessed at different spatial scales, from national to local [6]. However, as adaptation decisions are context-specific, and the adaptation decisions are often made at the local level, the local and regional scales are particularly relevant for assessment of adaptive capacity. Six major elements are identified to support CC policymaking at the local scale: (i) good governance; (ii) presence of national programmes facilitating local action; (iii) democratic and participatory nature of institutions; (iv) cities competences and authority to regulate climate-relevant issues; (v) the commitment of cities to take climate action; and (vi) availability of economic resources, knowledge and information, for example through the involvement of cities in national and transnational networks which allows the exchange of experience [15]. In sum, the adaptive capacity is directly related to the socio-economic and institutional capacity of a city, as well as, to the desire of adaptation of its citizens (Figure 1).

As result, there is a fundamental and persistent need to enhance understanding of the problem of $\mathrm{CC}$ and to enhance public support for adaptation policy. Enhancing understanding comes through awareness raising and communication to a wide audience including policymakers, planners and the public. Support for CC awareness can be promoted through national communication initiatives [16]; however, the implementation of adaptive measures is not directly related to provision of more information on climate impacts. The availability of up-to-date information does not easily translate into adaptive action due to a number of constraints, including the lack of trust in the practical relevance of the information in local decision-making. Thus, there is a clear requirement for the information relating to adaptation to be tailored to the local level. This also includes the access to appropriately downscaled CC conditions (for different scenarios) and their potential impacts. The distribution of adaptive capacity is the result of social and economic processes that affect not only the society as a whole, but also individuals based on their age, gender, health and social status [17]. Thus, equity in terms of even access to resources or decision-making processes is an important consideration in relation to resources and power in governing resources for adaptation [10]. Equity concerns also relate to the distribution of material and 
economic resources which are also often distributed unequally, resulting in a lower adaptive capacity in certain areas or with certain groups or individuals [18].

The differences between sensitivity, response capacity, and exposure can be illustrated with a simple example, referring to the effects of a flood on a city. In an urban area, the houses located in riparian areas are, in principal, more susceptible to flooding than the houses located in elevated areas (exposure). Depending on the type of construction materials used in dwellings (wood, brick, etc.), the houses will be more or less affected by a flood (sensitivity). Wealthier families have more resources available to repair infrastructures damaged by water (adaptive capacity). The magnitude of the final impact will also depend on the intensity, magnitude, and extension of the flood (attributes of the stressor).

\subsection{Lineages of urban vulnerability research}

The main lineages of research on urban vulnerability to $\mathrm{CC}$ are based on vulnerability in the general environmental change context: natural stressors, political economy (or ecology) and ecological resilience [8, 19]. Figure 2 presents a schematic of the evolution of the main lineages of urban vulnerability research over time. The arrows represent the recent efforts within each lineage to converge with other traditions and develop a more integrated understanding of the different dimensions and determinants of urban vulnerability. Should be noted that the Figure 2 reflect the lineages well known and perfectly defined (as described by [8]) as well as the expected development on this area.

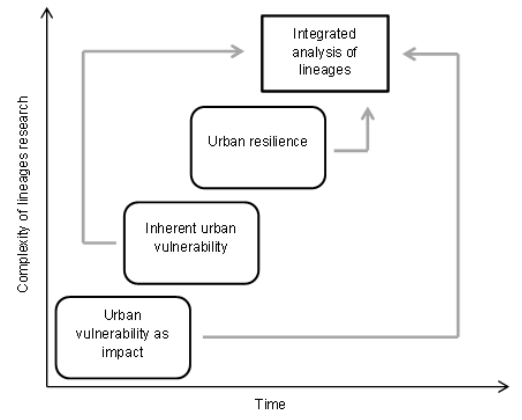

Figure 2: Lineages of urban vulnerability research (source: adapted from [8]).

The urban vulnerability as impact lineage addresses issues such as urban exposure or sensitivity to changes as a result of a stressor. There are two main types of research within this lineage. The first explores how changes in a parameter or combination of parameters (e.g. temperature, air pollution, precipitation) are related to impacts such as variations in crops productivity, air pollution exposure or mortality. In addition, several studies examine also the geographical characteristics of urban settlements (e.g. low elevation coastal zones, water scarcity, and steep slopes) that make city residents vulnerable to the impacts of CC. The second group of studies applies a scaled-down version of global CC scenarios to urban areas to estimate how parameters such as temperature and sea 
level rise will evolve in the future. Future climate impacts such as UHI effects, storms and heat waves, and its influence on atmospheric pollutants concentrations, are predicted under particular CC scenarios, through the application of both meteorological and air quality models. In some cases, adaptation options under realistic socioeconomic scenarios (considering future emissions, land use changes, evolution of population density, and others) are also explored, to evaluate how those impacts can be reduced [8]. However, this approach does not allow a complete understanding of a set of important questions, namely: how and why specific urban areas, or populations and sectors within cities are differentially affected; whether local stakeholders and populations are receptive to adaptation options and motivated to make the necessary changes; whether they have the necessary skills, awareness and resources to be able to adapt; and how their potential adaptation measures are constrained by the social, economic, political, and environmental circumstances in which they live [8].

Due to the need to answer these questions, the urban inherent vulnerability lineage emerged with the goal of exploring how and why particular cities or populations are more vulnerable or more able to adapt than others. Recent research has focused on urban areas, with limited socioeconomic power, which are expected to be more affected by the impacts of CC, as a result of both development and management deficits. These studies want to answer the questions of which urban areas are vulnerable, who within a city is vulnerable, and how and why particular urban populations are vulnerable. On the other hand, this approach does not, for example, analyse how exposure to, and impacts from changing stressors behave and evolve over time [3-5]. Urban inherent vulnerability differs from the urban vulnerability on the approach follow and its outcomes. According to Romero-Lankao and Qin [8], instead of viewing urban vulnerability as the end point of a linear process (e.g. projected impacts of CC on an exposure unit), it sees vulnerability as a dynamic process based on the decreasing ability of a city or its populations to cope with a set of societal and environmental stressors of which CC is only one. This decreasing ability is a result of the socioeconomic and institutional factors associated, for example, to the capacity to develop urban and structural policies.

The most recent lineage of urban vulnerability is related to the emerging application of resilience science, which reflects a general change from vulnerability to response-capacity building in recent $\mathrm{CC}$ research, with some attempts to explore vulnerability and resilience as two overlapping inherent properties of urban system. It is the interaction of both these properties with natural stressors and adaptation measures that may reduce or enhance accumulative disaster impacts [20]. This concept is explored in section 3.

The existence of different lineages of research on urban vulnerability also offers opportunities not only for understanding the linkages between the different dimensions involved, but also to promote synthesis and convergence of concepts. This is illustrated by recent efforts to integrate relevant urban knowledge from the disaster-risk management, CC and development communities (see Figure 2), and by recent research applying a more integrated version of the stressors and a climate vulnerability framework in an urban context [8]. As result, it is expected that the 
urban vulnerability research evolve for an integration of the existing lineages and the development of better integrated research approaches to help fully understand the nature of and interactions between impacts, stressors and their precursors, adaptive capacities, and actual adaptations. Ultimately, this lineage should be able to increase our ability to design and implement more effective response actions.

It is in this context that projects like CLICURB are included. This project allows the assessment of air quality under $\mathrm{CC}$ scenarios; as well as the evaluation of the influence of resilience factors on CC effects. The innovation, complex and multidisciplinary nature of the subject research, through trough an integrated approach that assesses $\mathrm{CC}$, urban land use, emission scenarios and air quality, with high spatial resolution, considering the main policy regulations and environmental targets, is the main research challenge under this project. It is expected that CLICURB project contributes to the boost of a better integrated research approach.

\section{Resilience of urban areas}

As discussed in section 2, the vulnerability concept of any system (at any scale) is a function of the exposure and sensitivity of that system to a stressed condition and the ability or capacity or of the system to cope, adapt or recover from the effects of those conditions. Understanding the factors that control the urban vulnerability to climate effects and to weather extremes, and the scales at which they operate, provides a framework for considering resilience. As result, in this section the concept of resilience, as well the conceptual linkages between it and vulnerability and adaptive capacity are explored. The links between resilience and vulnerability are highlighted.

The notion of resilience is gaining increasing prominence within the literature on cities and $\mathrm{CC}$, as result of a broad consensus that: (i) cities must become resilient to a wider range of perturbations and stressors in order to face $\mathrm{CC}$; and (ii) efforts to foster $\mathrm{CC}$ resilience must be bundled with efforts to promote urban development and sustainability. Enhancement of resilience is widely cited as a fundamental goal for both adaptation and mitigation efforts in cities and urban regions [21]. While different approaches and definitions of resilience exist, here are only considered those which help define the dimensions and determinants of vulnerability and adaptive capacity to global climate and environmental change within urban areas.

Terms such as "climate resilient", "climate-proofing", and "resilient city" are frequently used to emphasize the idea that cities, urban systems and urban communities need to be able to quickly recover from climate-related shocks and stressors. As result, a resilient city is characterized by its capacity to withstand or absorb the impact of a stressor through resistance or adaptation, which enable it to maintain certain basic functions and structures during an extreme event, and bounce back or recover from an event [22]. The concept of resilience does not include exposure but refers to the reaction of the system when exposed to perturbations [23].

Urban resilience studies are grounded in a diverse range of literatures, which can be classified into four categories: 
(i) Urban ecological resilience: Based on traditional notions of ecosystems resilience, defines urban resilience as the "ability of a city or urban system to absorb disturbance while retaining identity, structure and key processes" [8]. This type of studies has expanded from an initial focus on urban ecosystems, to the analysis of the linkages between the human-environment urban systems, to examination of cities and urban networks as complex adaptive systems [24]. Within this literature, extreme climate events and gradual climatic changes are regarded as stressors that affect cities and urban systems [25].

(ii) Urban hazards (stressors) and disaster risk reduction: Emphasis is placed on enhancing the capacity of cities, infrastructure systems, and urban populations to quickly and effectively recover from both natural and anthropogenic stressors. Recent work in this field, recognizing that $\mathrm{CC}$ is an emerging stressor for which urban areas must build resilience $[21,26]$ has been developing efforts to: quantify economic resilience to stressors; evaluate resilience of infrastructure systems and urban built environments; and, analyse how cities recover from extreme events [24]. The main outcome of this study is the identification of mechanisms and strategies to increase stressor resilience of urban communities [8], and, ultimately, develop models of community resilience based on a wide range of quantitative indicators [21] or measure variations in resilience of cities [27].

(iii) Resilience of urban and regional economies: This literature studies the evolution of urban and regional economic and industrial systems, through the use of the ideas and terminology from ecological resilience theory, emphasizing that climate change is one of many types of stressors that urban and regional economies face $[28,29]$. Recent studies in this scientific area analyse the linkages between diversity, volatility and growth of urban and regional areas, identify factors that explain why resilience is unequal across urban areas, and examines linkages between resilience and different economic development of cities and regions [36]. The emphasis on the relationship between resilience and geographical location raises important questions about the role of power and politics in influencing development paths and trajectories of urban areas [29].

(iv) Promotion of resilience through urban governance and institutions: This literature focuses on how different types of institutional mechanisms (financial instruments, insurance policies, regulatory proceedings, program formulation, and development of community participation and stakeholder involvement) affect the resilience of local environments [30] and how resilience thinking can influence the development of governance measures to promote adaptation to climate change [19]. These studies also considered how resilience principles can be used to promote sustainability in highly developed urban areas [24], and which characteristics of urban management can enhance climate resilience while at the same time reducing vulnerability of urban population [31]. The understanding, by the decision makers, that the successful of adaptation measures at local scales is strongly influenced by educational, cultural and social cohesion, will promote a dissemination of information and awareness of local communities regarding urban vulnerability to climate change. 
There is much overlap among these different sets of literature, each emphasizing different facets of urban resilience and each focused on different components of cities and urban systems.

In the context of resilience, the Committee of the Regions on EU Strategy for Adaptation to Climate Change (Directive 2013/C 356/07) considers adaptation to be: (i) a holistic agenda, cutting across systems, sectors, spatial scales and timescales; (ii) one element of a broader strategy needed to build the resilience of Europe and the cities and regions within it; and (iii) a process of identifying and subsequently reducing risks from extreme weather and climate stressors, thereby lessening the intensity of related shocks.

It is in this political framework the so-called resilient factors appears as crucial measures to improve cities resilience, offering a preparative support for dealing in advance with the effects of CC and related extreme events. Resilient options can range from actions (also called 'soft measures') that build adaptive capacity (e.g. sharing information, creating supportive institutional framework) or establish management systems and supportive mechanisms (e.g. better land management planning, insurance mechanisms) to concrete resilient measures, often referred to as 'grey' (e.g. infrastructure development) or 'green' (eco-system based measures) measures. The creation of resilient infrastructure systems may require large scale changes to the way infrastructures are planned, designed, managed and maintained. In many cases, advanced technology and instrumentation can facilitate the development of systems with greater ability to respond to unexpected impacts.

The future development of a resilience framework represents an opportunity to improve planning processes and land use management and increasing the responsiveness of local communities and the built environment. The process also represents an opportunity to improve the management of extreme weather events.

\section{Final remarks}

The current research on urban vulnerability faces a tension between the need to represent dimensions and factors involved, and a desire to identify the potential to response and resilience across urban areas. The comparative analysis of the concepts of vulnerability, resilience, and adaptive capacity made in this work shows that there is no generally accepted meaning for these concepts, as they are applied for different areas of research. As result, both similarities and differences and, in some cases, contradictions between the concepts were observed. Despite that, it is consensual that vulnerability is a function of the nature, magnitude and frequency of $\mathrm{CC}$ and the degree to which the system is exposed according to its sensitivity and adaptive capacity.

Understanding the conceptual framework of urban vulnerability to global climate and environmental change is the first step in accepting that there are no invulnerable cities. Identifying specific vulnerabilities of any urban area is a complex and lengthy process, demanding in terms of information and knowledge, and in constantly need of being updated. Every urban area has its own vulnerability which under identical conditions of $\mathrm{CC}$ will depend on: localization, natural 
conditions, population density, urban morphology; characteristics of urban infrastructures, and types of economic and social services. These factors should be considered as input to evaluate the potential impacts that a city is subject.

The concept of resilience has been applied in urban areas in the recent research, and appears to be related to one of the components of vulnerability, the same that is called adaptive capacity (or coping capacity, coping, and capacity of response). However it is unclear if resilience includes adaptive capacity, or is an element of the latter, although the conceptual links between these concepts are well defined. On the other hand, for some authors, it seems natural to see vulnerability and resilience as related properties of a system, and thus, being the opposite of each other.

Looking at the set of literature analysed, and in accordance with the recent European frameworks, is expected that research on vulnerability will evolve focused on the search for measures that make a city more resilient and less vulnerable, in order to be able to adapt to variability and $\mathrm{CC}$.

\section{Acknowledgements}

The authors acknowledge the financial support of CLICURB and MAPLIA projects (EXCL/AAG-MAA/0383/2012 and PTDC/AAG-MAA/4077/2012), supported in the scope of the European Funds through COMPETE and by National Funds through the Portuguese Science Foundation (FCT) within project PEstC/MAR/LA0017/2013. An acknowledgement to the Portuguese 'Ministério da Ciência, da Tecnologia e do Ensino Superior' for the PhD grant of Sandra Rafael (SFRH/BD/103184/2014) and the post-doc grant of Helena Martins (SFRH/BDP/66874/2009).

\section{References}

[1] Pelling M and Blackburn S. 2014. Megacities and the CoastRisk, Resilience and Transformation. Earthscan from Routledge. ISBN: 9780415815123.

[2] Grimmond CSB. 2011. Urban Climate in the Coastal Zone: Resilience to Weather Extremes. Megacities and the Coast: Transformation for resilience. A preliminary review of knowledge, practice and future research. LandOcean Interactions in the Coastal Zone (LOICZ). Chapter 7.

[3] Parnell S, Simon D, Vogel C. 2007. Global environmental change: conceptualising the growing challenge for cities in poor countries. Area, 39, pp. 357-369.

[4] Satterthwaite D, Huq S, Pelling M, Reid H, Romero-Lankao P. 2007. Adapting to climate change in urban areas: The possibilities and constraints in low- and middle-income nations. Human Settlements Discussion Paper: Climate Change and Cities 1.

[5] Pelling M. 2008. The vulnerability of cities to disasters and climate change: a conceptual introduction. In Coping with Global Environmental Change, Disasters and Security - Threats, Challenges, Vulnerabilities and Risks, Hexagon Series on Human and Environmental Security and Peace, vol 5. 
Edited by Brauch HG, Spring UO, Mesjasz C, Grin J, Kameri-Mbote P, Chourou B, Dunay P, Birkmann J. Springer.

[6] EEA, European Environmental Agency. 2012. Urban adaptation to climate change in Europe - challenges and opportunities for cities together with supportive national and European policies. EEA Report No. 2/2012, Copenhagen. Luxembourg: Publications Office of the European Union. ISBN 978-92-9213-308-5. (DOI:10.2800/41895).

[7] Fussel H. 2007. Vulnerability: a generally applicable conceptual framework for climate change research. Global Environ Chang 17, pp. 155-167. (DOI: http://dx.doi.org/10.1016/j.gloenvcha.2006.05.002).

[8] Romero-Lankao P and Qin H. 2011. Conceptualizing urban vulnerability to global climate and environmental change. Current opinion in Environmental Sustainability 3, pp. 142-149. (DOI: http://dx.doi.org/ 10.1016/j.cosust.2010.12.016).

[9] Adger W.N. 2006. Vulnerability. Global Environ Chang 16, pp. 268-281.

[10] IPCC (Intergovernmental Panel on Climate Change). 2001. Technical summary: climate change 2001: impacts, adaptation, and vulnerability. A Report of Working Group II of the Intergovernmental Panel on Climate Change. URL: http://www.grida.no/climate/ipcc_tar/wg2/pdf/ wg2TARtechsum.pdf.

[11] Gallopín G.C. 2003. Box 1. A systemic synthesis of the relations between vulnerability, hazard, exposure and impact, aimed at policy identification. In: Economic Commission for Latin American and the Caribbean (ECLAC). Handbook for Estimating the Socio-Economic and Environmental Effects of Disasters. ECLAC, LC/MEX/G.S., Mexico, D.F., pp. 2-5.

[12] Turner II, Kasperson R.E, Matson P.A, McCarthy J.J, Corell R.W, Christensen L, et al. 2003. A framework for vulnerability analysis in sustainability science. Proceedings of the National Academy of Sciences of the United States of America 100, pp. 8074-8079.

[13] Smit B, Wandel J. 2006. Adaptation, adaptive capacity and vulnerability. Global Environ Chang 16, pp. 282-292. (DOI: http://dx.doi.org/10.1016/ j.gloenvcha.2006.03.008).

[14] IPCC. 2007. Climate change 2007: Synthesis report. Contribution of Working Groups I, II and III to the fourth assessment report of the Intergovernmental Panel on Climate Change, Cambridge University Press, Cambridge, United Kingdom.

[15] Martins R.D and Ferreira L.D.C. 2011. Opportunities and constraints for local and subnational climate change policy in urban areas: Insights from diverse contexts. International Journal of Global Environmental Issues 11, pp. 37-53.

[16] Swart R, Biesbroek R, Binnerup S, Carter T.R, Cowan C, Henrichs T, et al. 2009. Europe adapts to climate change comparing national adaptation strategies. PEER, Helsinki.

[17] IPCC. 2012. Summary for Policymakers. Managing the Risks of Extreme Events and Disasters to Advance Climate Change Adaptation. A Special 
Report of Working Groups I and II of the Intergovernmental Panel on Climate Change, Cambridge University Press, Cambridge, United Kingdom and New York, NY, USA.

[18] Keskitalo E.C.H (ed.). 2010. Developing adaptation policy and practice in Europe: multi-level governance of climate change, Springer. Dordrecht, New York, United States.

[19] O’Brien K, Hayward B, Berkes F. 2009. Rethinking social contracts: building resilience in a changing climate. Ecol. Soc. 14, Art 12. URL: http://www.ecologyandsociety.org/vol14/iss2/art12/.

[20] Leichenko R. 2011. Climate change and urban resilience. Current opinion in Environmental Sustainability 3, pp. 164-168.

[21] Cutter SL, Barnes L, Berry M, Burton C, Evans E, Tate E, Webb J. 2008. A place-based model for understanding community resilience to natural disasters. Global Environ Chang 18, pp. 598-605.

[22] Twigg J. 2009. Characteristics of a Disaster-Resilient Community: A Guidance Note. DFID Disaster Risk Reduction Interagency Coordination Group.

[23] Gallopín G. 2006. Linkages between vulnerability, resilience and adaptive capacity. Global Environ Chang 16, pp. 293-303.

[24] Ernstson H, Van der Leeuw S, Redman C, Meffert D, Davis G, Alfsen C, Elmqvist T. 2010. Urban transitions: on urban resilience and humandominated ecosystems. AMBIO: A Journal of the Human Environment 39, pp. 531-545. (DOI: 10.1007/s13280-010-0081-9).

[25] Coaffee J. 2008. Risk, resilience, and environmentally sustainable cities. Energy Policy 36, pp. 4633-4638.

[26] Coaffee J and Rogers P. 2008. Rebordering the city for new security challenges: from counter-terrorism to community resilience. Space and Polity 12, pp. 101-118.

[27] Zhou H, Wang J, Wan J, Jia H. 2010. Resilience to natural hazards: a geographic perspective. Nat Hazards 53, pp. 21-41.

[28] Pendall R, Foster K, Cowell M. 2010. Resilience and regions: building understanding of the metaphor. Cambridge Journal of Regions, Economy and Society 3, pp. 71-84.

[29] Pike A, Dawley S, Tomaney J. 2010. Resilience adaptation and adaptability. Cambridge Journal of Regions, Economy and Society 3, pp. 59-70.

[30] Ostrom E. 2010. Polycentric systems for coping with collective action and global environmental change. Global Environ Chang 20, pp. 550-557. (DOI: http://dx.doi.org/10.1016/j.gloenvcha.2010.07.004).

[31] Tanner T, Mitchell T, Polack E, Guenther B. 2009. Urban Governance for Adaptation: Assessing Climate Change Resilience in Ten Asian Cities. IDS Working Papers (p. 315). http://www.ntd.co.uk/idsbookshop/details. asp?id=1069. 